\title{
Architecture, as a tool to raise awareness to climate change and sea level rise: case of Libyan coastal city of Zuwara
}

\author{
Manal Chalgham* \\ Bahar Başer Kalyoncuoğlu**
}

\begin{abstract}
The effects of climate change are no longer just a possibility we will face in the future. Droughts, wildfires, storms, sea surges, and much more, are climate change-related risks that communities around the world are facing today, coastal communities are particularly under the risk of floods and sea-level rise, but how aware are these communities of these threats? This study sets out to assess social awareness to climate change amongst the residents of the coastal Libyan city of Zuwara, which faces the risk of floods and sea level rise (SLR). The awareness level of the society about the factors of climate change can create significant barrier in front of mitigation and adaptation process. From this point of view, the study suggests that using a tool that publicly understandable and having familiarity with can have a greater impact on the level of awareness. Therefore, it has been focused on the role of architecture as a tool to raise awareness of the risks of climate change. The research methodology relies on a case study with future projections regarding Sea level rise (SLR) under different Representative concentration pathway (RCP), and a social survey designed in three stages: First step is measuring the level of awareness of residents of the city, then in the second attempt to rise it using architecture as an educative tool, and finally remeasuring the level of awareness in order to test the effectiveness of architecture as proposed tool. The questionnaire was distributed online to a sample of 100 people including participants who are of professional backgrounds in architecture and built environment. Statistical analysis of the questionnaire was divided into two stages, first, measuring the level of general awareness of the respondents about their living environment and climate change, then measuring the level of improvement in awareness about climate change during the survey. The second section of the questionnaire was formulated based on Likert scale, and to test the study's hypotheses, (T - Test) and Independent Samples Test, were used. Survey results have shown an increase in the degree of awareness between participants when comparing answers before stage two and after, suggesting that using architecture as an educative tool to raise awareness about climate change; is effective.
\end{abstract}

Keywords: climate change, sea level rise, public awareness, Libyan coast, Zuwara city.

\section{Introduction}

Climate change is affecting different parts of our planet in different ways and due to global warming sea level is rising consequently, probably the coastal cities may experience the first hit. Scientists expect that the sea level will rise by two meters by the year 2100 . However, some 
opinions see these estimates are pessimistic, regarding realistic estimates to be in the range of 90 centimeters (Thead, 2016) either way. On the other hand, size of the risk on coastal communities will be undeniably the greatest one, especially if we consider the fact that about $40 \%$ of the world's population lives within 100 kilometers off the coast (Maul \& Duedall, 2019). Therefore, the fight against climate change must take place on several fronts, ideally, in the form of cooperation between citizens, governments, and experts, in order to combat the threats to these communities. Pro-active, planned adaptation is highly necessary to reduce vulnerability, however, implementation of adaptation strategies can be challenging at times due to the misunderstanding of the concept of climate change amongst the public (Bord, Fisher, \& Robert, 1998), therefore, making the implementation of mitigation and adaptation plans are more difficult to put into practice (Lorenzoni, \& Pidgeon, 2006). Attempts to communicate about the risk of climate change often remains within the scientific or specialized framework, and the focus remains on information rather than methods of communicating it to the public, and in this study, we prove that it often fails to produce the desired effect among the public (Lieske, 2012). Our research suggests that people can be less reluctant to act positively regarding climate change if they can relate on a local level to the issue, realizing that climate change will have an effect on their local environment, familiar surroundings, and the ecosystem services upon which they rely on. Using a tool that public understands and familiar with will help with raising the level of awareness and also encourage positive change. In the context of climate change effects on our built environment, this research will focus on architecture represented in the built environment. Especially it will focus on the potentials of architecture in order to help guide scientists and policymakers to have a more successful discussion about climate-related effects through using the people's homes and how climate change puts them under immense threat and having effects on the awareness of climate change in public level.

Adequate level of awareness among the members of the community is achieved when most agree on the importance of certain issue for this society, and so is the case when trying to change the attitude of a society towards climate change (Whitmarsh, \& Upham, 2013).

\section{Methodology}

\subsection{Introduction of Case Study}

The Libyan coastal city of Zuwara was chosen as the case study area, since it is one of the coastal cities at risk of drowning due to the rising sea level expected to occur as a result of climate change. Located in the West Coast of Libya, 120 kilometers west of the capital Tripoli and near the Tunisian border, around 60 kilometers east of the border Zuwara is a small city of a 42.546 number of people living in it (Zuwara's Office of Civil Status, 2019). Though it is located on the Mediterranean Region, is still affected by the desert climate that dominates the majority of Libya. This gives Zuwara a BHS or a semi-arid climate, characterized with hot summers and warm winters with fluctuating rates of annual precipitation avareging less than $250 \mathrm{~mm}$. (LECRC, 2019, pp.14-19). The city of Zuwara appears as consisting of two main types of soil, one is described as a desert soil with a layer of concentrated limestone, as well as a shallow newly formed soil on top of incoherent stone materials with salty soils with some sandy beach dunes, this, and the widespread of the "Sabkha" 1 formations and salty groundwater, leads the city to be destitute in terms of vegetation cover though gatherings of Date Palm Trees, and Tamarisk Bushes grow in the areas of sand covered flat Sabkha (Poland Bureau of Municipal Projects, 1980, p.14).

${ }^{1}$ Sabkha: saline soils, consisting of sandy carbonate mud soils, usually found in coastal and arid regions. (Ahmed \& Zaied, 2012) 


\subsection{Current Situation of the Site}

There are several factors that make the city of Zuwara particularly vulnerable to climate change, sea surges, and level rise, some of these factors are natural; like the geographic nature of the city on the Mediterranean, very close to the shoreline. Also; because the majority of the city is flat, with the highest land ranging between 5 to 10 meters; accounts only for $2.6 \%$ of the total city plan, and

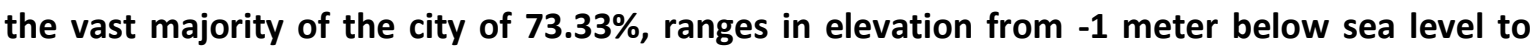
merely centimeters above it (Figure 1 ).

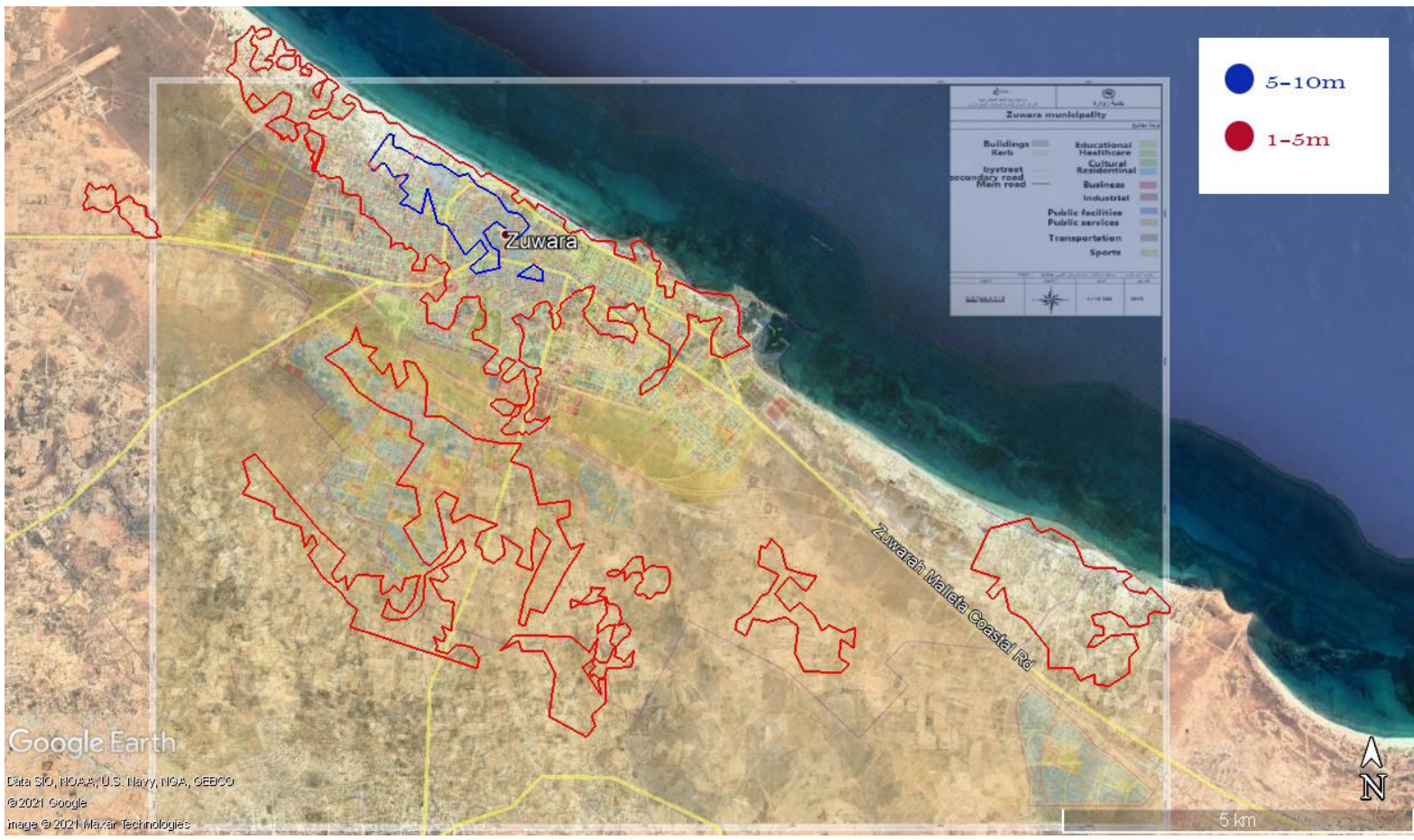

Figure 1 Shows the different elevations of the city. The area marked in blue ranges from $5 \mathrm{~m}-10 \mathrm{~m}$ above sea level. Area marked in red ranges between $1 \mathrm{~m}-5 \mathrm{~m}$ above sea level. While the rest of the map ranges between $0.9 \mathrm{~m}$ above sea level and $-2 m$ below it.

Man-made factors that make the city more vulnerable to climate effects can be traced back to government/municipality actions and decisions, like designing the city plan to be very close to the shoreline, going as close to the sea as $\mathbf{5 0}$ meters and less in. Moreover, according to Head of Department in Zuwara city Planning Office there are haphazard buildings in areas near the beach that are illegally constructed out of the city plan which are under the exact risk of SLR (Alnajjar, personal communication, 2020).

The sand dunes scattered in this area act as an important ecological component that plays a vital role in protecting the local environment and ecosystem, as well as the city from potential sea surges. Beach-sand-quarrying is an individual action that make the city more vulnerable. Sand is usually an impermeable barrier against land erosion against the mighty power of waves of seas and oceans, Also, removal of sand for construction and other purposes can accelerate beach erosion and raise the risk of coastal flooding. The act of using beach sand in construction in the city of Zuwara has been seen often recently (Figure 2). It is not clear whether ignorance of the consequences of this action behind it or a lack of concern for these consequences. 


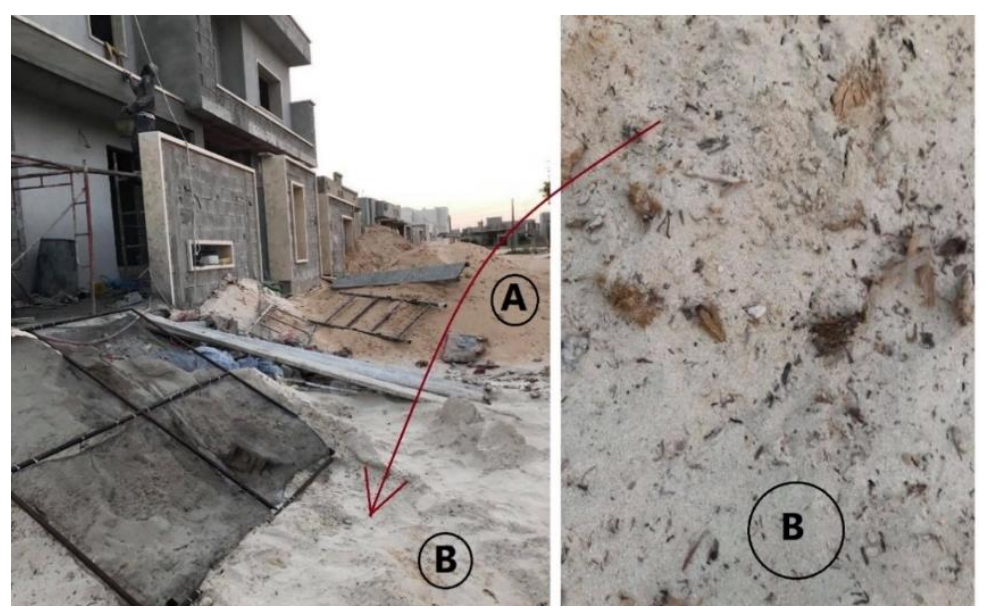

Figure 2 Photo taken by the researcher (2019) showing a building under construction using beach sand (B) alongside normal construction sand (A)

The city of Zuwara has already experienced coastal flooding in winter seasons, pictures in (Figure 3) were taken in February 2019, although such event has not been eagerly frequent or intense. Studies show that with current projections and without adaptation strategies being applied, coastal flooding will not only become more intense, but also more frequent (Moatti, \& Thiébault. 2016).

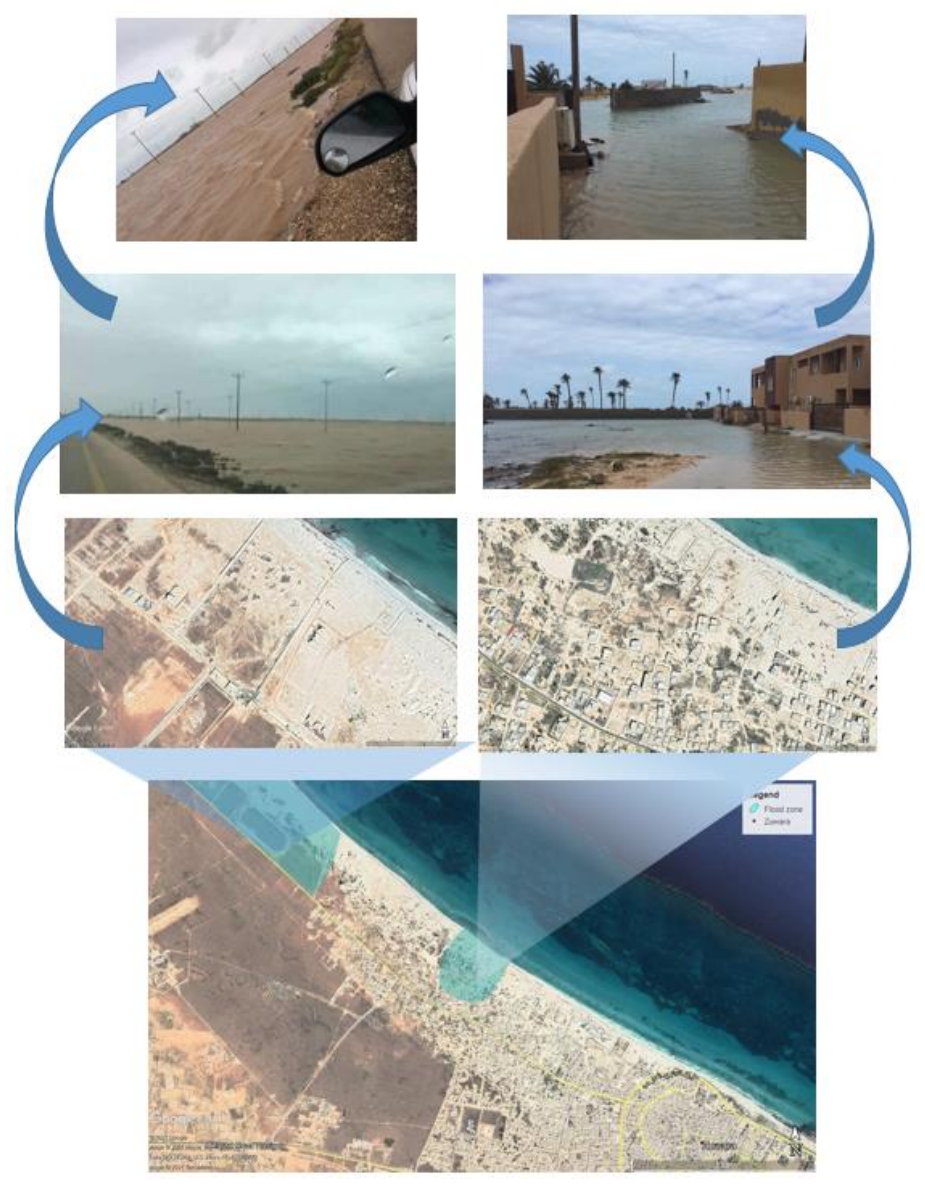

Figure 3 Coastal flooding in Zuwara-Feb-2019

\subsection{The Future Projections of the Site}

How will the future of Zuwara City look like in upcoming decades? This relies on many factors, including the acceleration rate of global warming and how hot it will get, which in turn relies on the 
behaviours of today. Using data from Climate Central's Program on SLR, (Climate Central, 2014) two methods were used to visualize future risk on the city due to climate change and sea-level rise. The first is "Coastal Risk Screening Tool" which explores risks over time, incorporating multiple pollution scenarios, leading sea-level rise models, relying on projections from Mid-range (Kopp et al. 2014), and the most accurate available elevation data available to explore coastal flood risk and sea-level rise projections by decadal year. By choosing decadal year marks of 2100, and two different pathways, RCP4.5 as the best plausibly possible scenario in (Figure-4) and the RCP 8.5 as the worst visualized scenario in (Figure-5) and which, unfortunately, current emissions are tracking close to (Moatti \& Thiébault 2016).

These scenarios reflect threats from permanent future sea-level rise, as well as the annual flood, areas lower than the water level, and with an unobstructed path to the sea are recognized as at risk of flooding and are shaded red in the maps. Areas, which are below the water level but that appear to be protected by ridges are not recognized as being at risk of flooding, and therefore, not shaded.

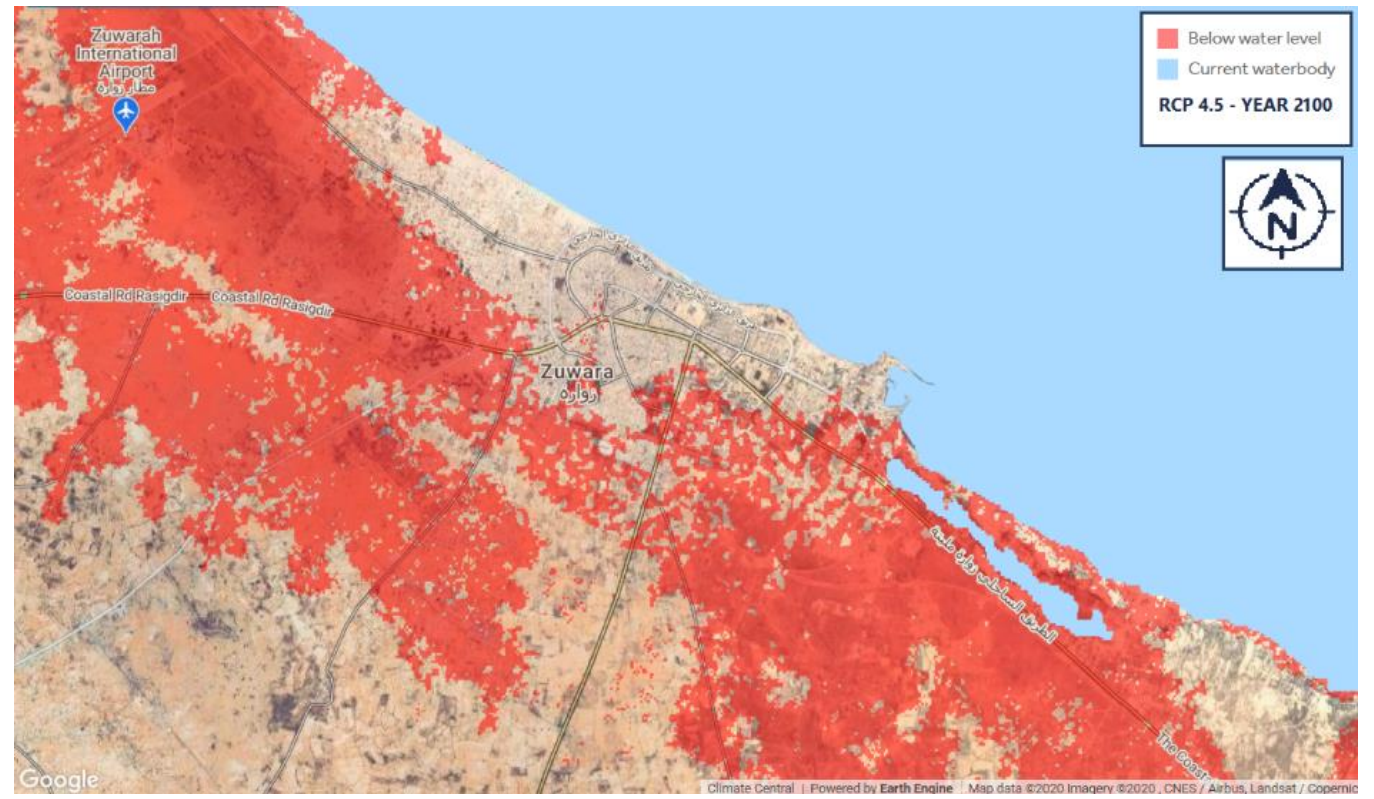

Figure 42100 , RCP 4.5 years scenario visualization on the map of Zuwara. (Climate Central, 2014)

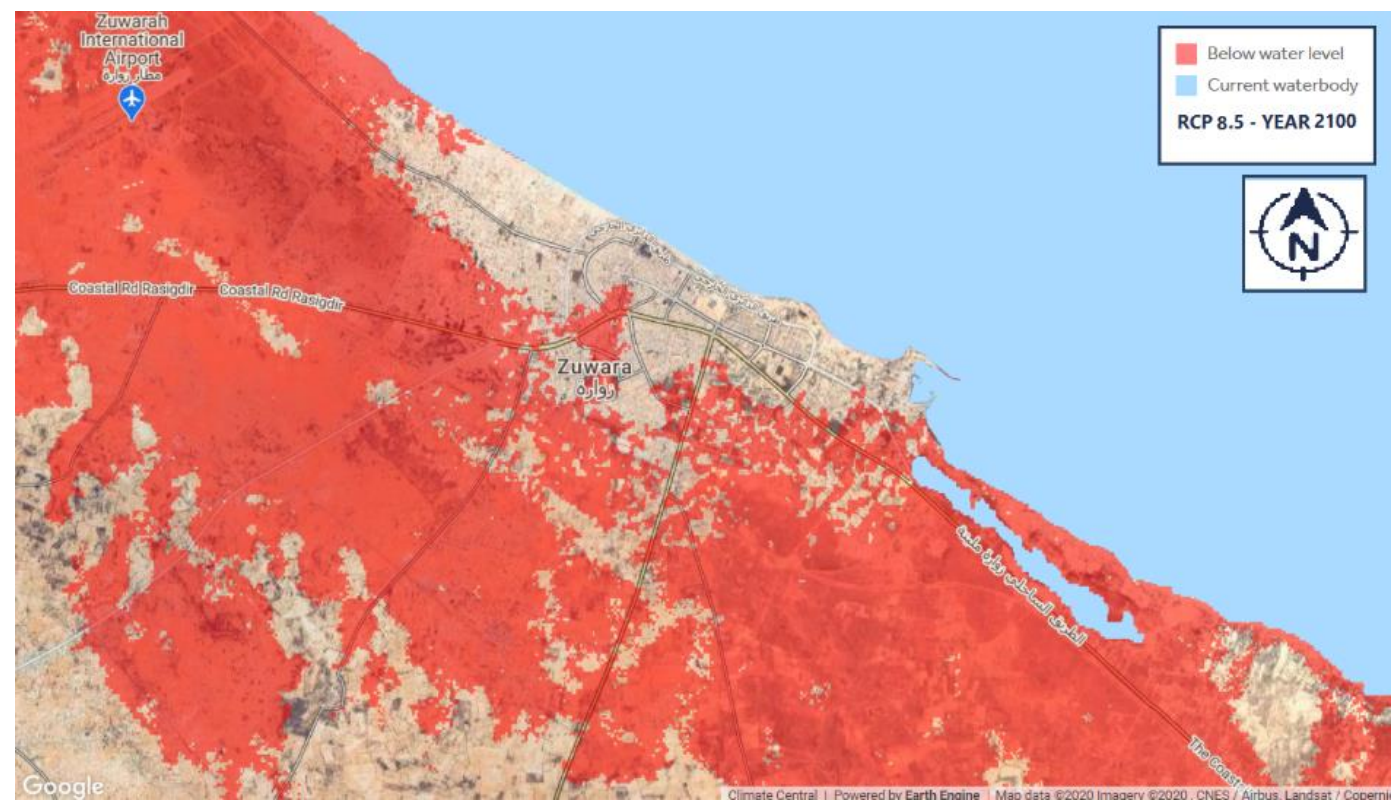

Figure 5 2100, RCP 8.5 years scenario visualization on the map of Zuwara. (Climate Central, 2014) 


\subsection{Building Typology of the City of Zuwara}

The urban development of the city took a circular shape around the city center (Figure-6), where the old city is, building types get newer by going further away from that point labeled as (Type A) Those are ground-level buildings with center courtyards (Figure-7), usually found in a linear form and they have one longitudinal façade facing the street in the old city, while the other sides are surrounded by other houses. These houses have an internal courtyard with the dimensions of the yard about $4 \times 6$ meters, and the height reaches 3.5 meters. Surrounding that there is the altered traditional building (Type B) with side courtyards (Figure-8). Both use similar materials of locally available materials found in nature, such as limestone, used in bearing and supporting walls, while some are burned in primitive furnaces to make gypsum material that is used as mortar in construction, and part of these burned stones are quenched with water and is made for plaster and paint. materials used in the roofs are longitudinally split trunks of palm trees, sometimes sticks are used with them intertwined with ropes, and dry seaweed is used to fill the voids and as an insulator for the roof (Helmy, 2020). Many of these buildings today have been modified and modern materials have been added to them, such as concrete.

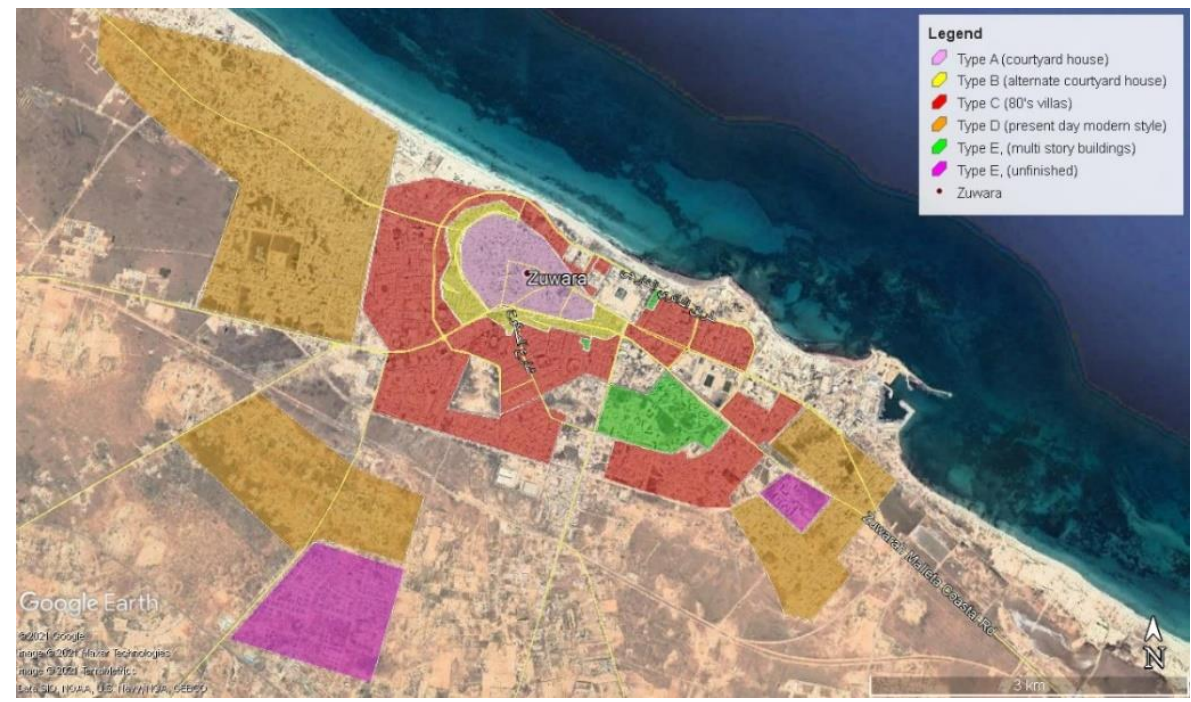

Figure 6 Building types and locations in the city

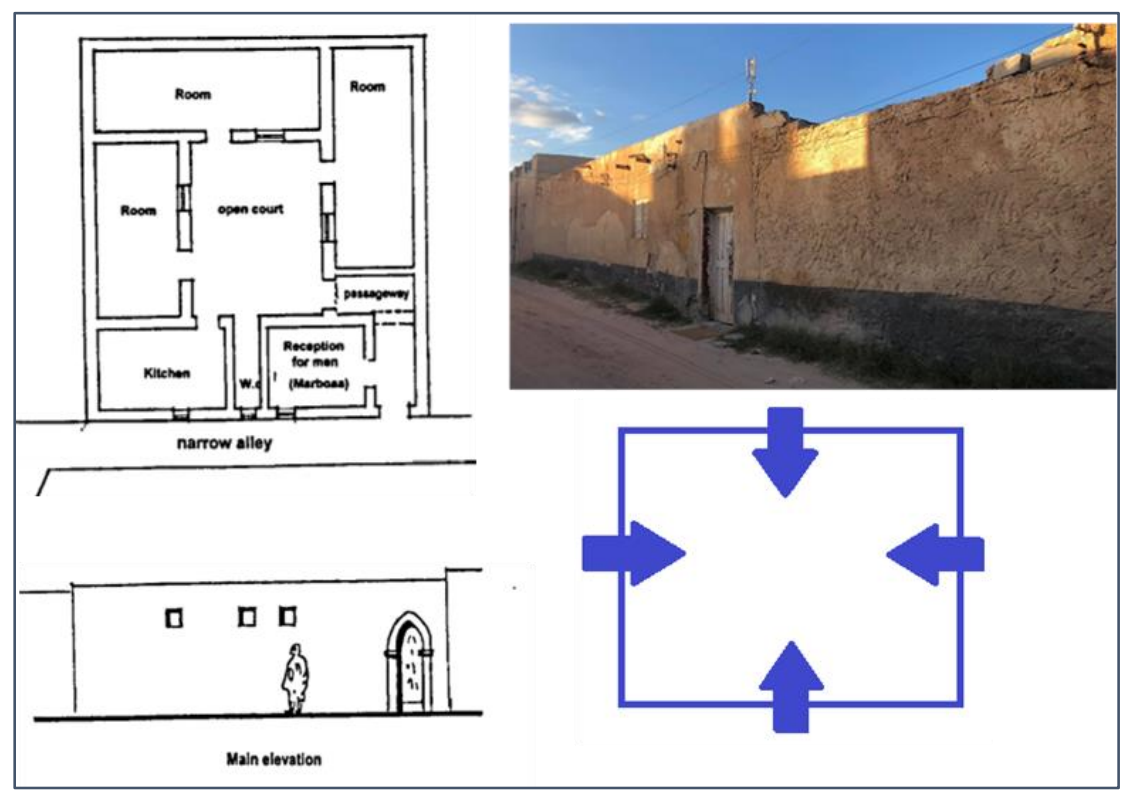

Figure 7 Building type $A$ in the city, main building material was locally available limestone. 


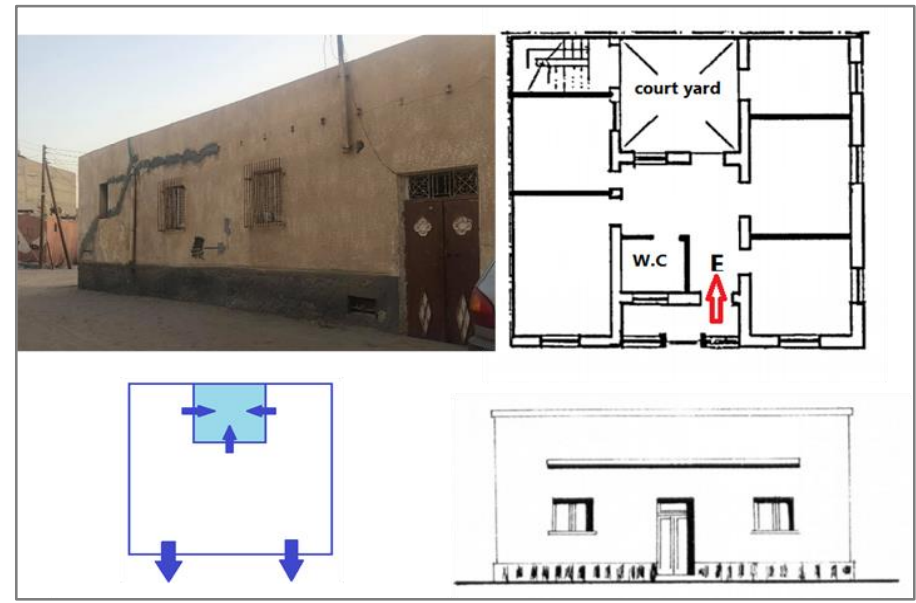

Figure 8 Building type B in the city

(Type C) shown in (Figure-9) and (Type D) shown in (Figure-10), are fairly similar. These are private units, one to two-story, type $\mathrm{D}$ differs from type $\mathrm{C}$ only in decoration elements and the absence of using Limestone and relying solely on concrete and hollow cement bricks.

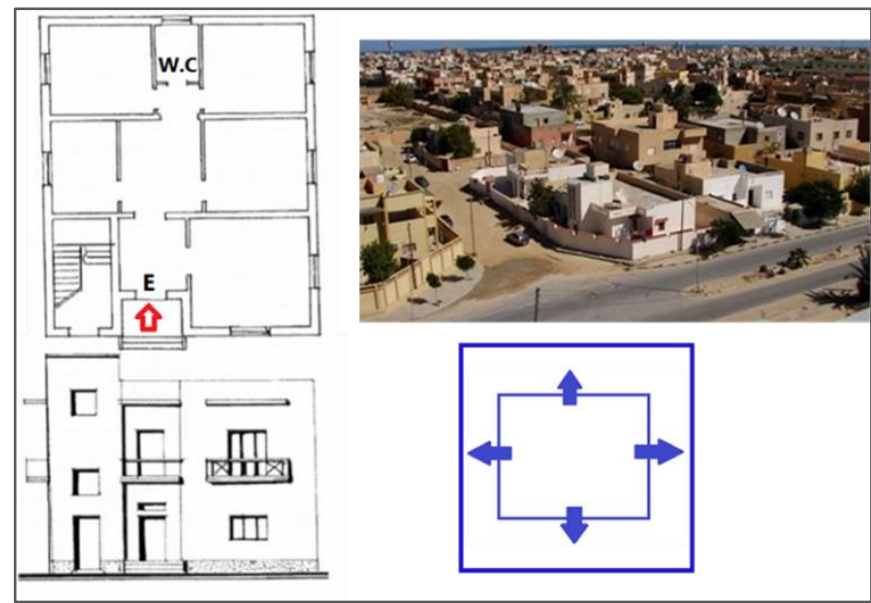

Figure 9 Building type $\mathrm{C}$ in the city

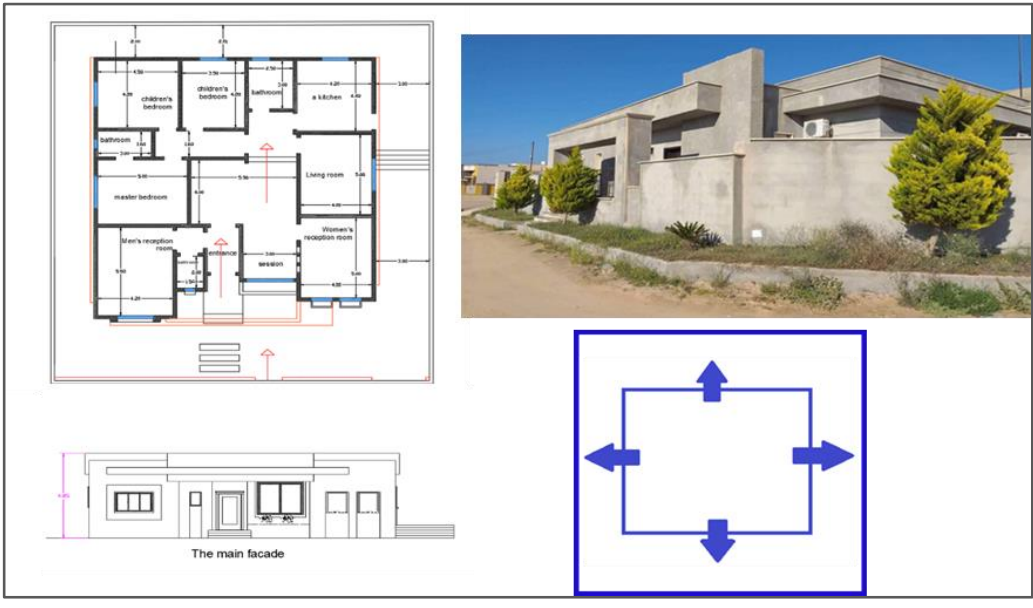

Figure 10 Building type $D$ in the city

Finally there is (Type E) shown in (Figure-11). These are a multi-story type buildings consisting of three to six floors, these are modern flat-roofed, concrete buildings, and they make a small percentage of the city's residential units compared to single private homes. 

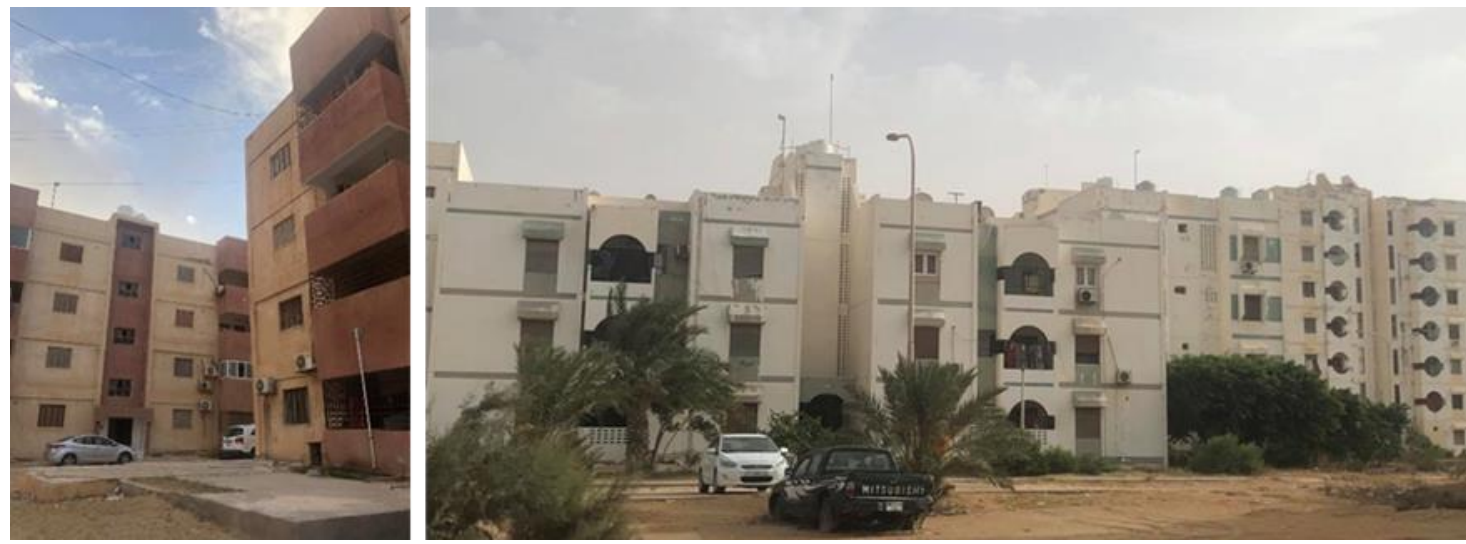

Figure 11 Building type $\mathrm{E}$ in the city

The differences between these types naturally affects their exposure to the risk of climate change and sea-level rise. The biggest difference we notice is between the traditional building (Types A-B) and the modern building (Types C), where the complete difference in shape, size, height, and building materials, as (Types A-B) buildings are often located in the central area of the city. One of the factors that make these buildings safer is their location, where they are located in a relatively high area compared to the rest of the city. However, the buildings are very low lying and are not raised above ground level, rather the contrary, most of these buildings are one or two steps below street level and with no reinforced concrete foundations, which makes them weaker in resisting climatic conditions. This is observed in rainy seasons, when these buildings are more exposed to the risk of rainwater flowing into them. Unlike the modern (Type C), where people have noticed these vulnerability factors, and started raising the buildings a little higher than the ground by two to three steps above street level. Another protection element that people used in buildings (Type C) is moving the courtyard to the outside, which creates a buffer zone between the main building and external environmental elements. This is not a sufficient solution of course considering the factors that put them under threat from climate change risks, like their closeness to shore, low ground level, poor infrastructure, and lack of attention to buffer zones.

\section{Research Design and Data Analysis}

The study was designed in the form of a questionnaire distributed among the population of the city, but before that a theoretical and field study of the case area and its surrounding conditions was carried out, and the data collected from this study was used in the questionnaire, which tests the research hypotheses. The main hypothesis states that "architecture can be used as a tool for creating consciousness and raising awareness between people on the effects of climate change" especially on human activity and environment, as well as the secondary hypothesis, which are:

- Public awareness of climate change risks is insufficient.

- Public awareness of climate change risks can be raised by using architecture as an educative tool.

- The role of professionals on the ways to overcome the risks of climate change is insufficient.

- Architecture can be used as a tool to motivate decision-makers to work on a strategy to combat risks of climate change.

Which all can be tested through measuring these variables:

1- People's awareness of the problem of climate change and the danger of sea level rise to the city of Zuwara. 
2- The change of people's awareness of the climate change problem after using the architectural environment as an educational tool.

3- The level of people's willingness to make change, if their awareness of the matter increases.

4- Level of awareness against different backgrounds of the participants of the survey.

The questionnaire is designed to be of three stages. First, the study sample has been identified in terms of demographic information and level of awareness regarding the problem of climate change and sea level rise, especially on the city of Zuwara. In the second stage, in order to raise awareness on the risks of climate change in the city, an information package about risks and threats on Zuwara city has been presented to the respondents with visual documents (diagrams and photos of the city) and architectural references. The third and final stage is where some questions from the first stage has been repeated in order to test if an increase in awareness in the survey sample.

\subsection{Statistical analysis of the questionnaire}

The questionnaire has been divided into two parts as follows:

- The first section: included the social and demographic information of the study sample (name - gender - age - marital status - educational level - field of work - monthly income number of family members - type and age of residence - the area of residence).

- The second section: It included two axes:

- The first axis is measuring the level of general awareness of the respondents about their living environment and about climate change.

- The second axis is measuring the level of improvement in awareness about the climate change during the survey. The second section of the questionnaire has been formulated based on Likert scale; the opinions, scores, weighted averages, relative weights and scores can be followed on the Table 1.

Table 1 Opinion, scores, weighted averages, relative weights, and score

\begin{tabular}{|l|l|l|l|l|l|}
\hline \multicolumn{2}{|l|}{ Scale options } & Score & Weighted average & Aggregate mean & Awareness level \\
\cline { 1 - 5 } $\begin{array}{l}\text { Strongly } \\
\text { Disagree }\end{array}$ & Not at all & 1 & $1.0-1.79$ & $1.0-2.3333$ & Low awareness \\
\hline Disagree & No & 2 & $1.8-2.59$ & $2.3334-3.6666$ & Medium awareness \\
\hline Neutral & I don't know & 3 & $2.6-3.39$ & $3.6667-5.0$ & High awareness \\
\hline Agree & Maybe & 4 & $3.4-4.19$ & & \\
\hline Strongly Agree & Yes & 5 & $4.2-5.0$ & & \\
\hline
\end{tabular}

To achieve the objectives of the study and answer its questions, the SPSS program was used to apply the following statistical methods:

1-Calculating the frequencies and percentages of social and demographic information for the study sample.

2-The graph to illustrate the percentages of social and demographic information for the study sample.

3-Calculating the weighted average, the standard deviation, the combined mean, and the level of awareness for each of the questionnaire statements, and for each axis of the questionnaire; to recognize the trends of the study sample.

4-To test hypotheses for the study Paired Samples and Independent Samples T-Test is used. 


\section{Findings of the Questionnaire}

\subsection{Socio-demographic information of the respondents}

The survey questions were randomly distributed to a sample size of 100 respondents, of which males are $51 \%$, and females are $49 \%$, with the highest age grope of participant of $30 \%$ of the respondents ranging between 26y and 35y and $98 \%$ of the respondents are of the age group (from 18 to 65 ), which gives an impression of confidence about the ability of the respondents to express their opinion based on their ages. As for education level; $77 \%$ of the respondents are of university level and above, which gives the impression of confidence about the ability of the respondents to express their opinion based on their educational level, and $23 \%$ of the study sample work in engineering, architecture, or urban planning fields.

\subsection{Measuring the awareness of the people of Zuwara}

The questionnaire was dedicated to measuring the level of general awareness of the respondents about their living and architectural environment and about climate change and the risk that it imposes, as well as using the architectural elements as a tool to raise this awareness. This is done by measuring people's awareness of the problem of climate change and the danger of sea level rise to the city of Zuwara. In order to achieve this, averages, standard deviations and the degree of awareness of the respondents was calculated on the problem of climate change and the danger of sea level rise on Zuwara. Table 2 shows the averages, standard deviations, the difference between the two averages, the degree of awareness and familiarity of the research main terms and variables, and the order of importance.

Table 2 Consciousness to search variables between participants of the survey

\begin{tabular}{|c|c|c|c|c|c|c|}
\hline $\begin{array}{l}\text { Ques- } \\
\text { tion. } \\
\text { NO }\end{array}$ & $\begin{array}{l}\text { Vari- } \\
\text { able. } \\
\text { NO }\end{array}$ & The research variables & Average & $\begin{array}{l}\text { Sstandard } \\
\text { deviation }\end{array}$ & $\begin{array}{c}\text { Degree of } \\
\text { consciousness }\end{array}$ & $\begin{array}{l}\text { Rank in order } \\
\text { of importance }\end{array}$ \\
\hline Q-14 & V.1 & The familiarity of climate change as a term & 3.18 & .857 & Medium & 11 \\
\hline Q-16 & $\mathrm{V} .2$ & Accepting climate change as a serious problem & 4.03 & .915 & High & 4 \\
\hline Q-17 & V.3 & $\begin{array}{l}\text { Observing the change in environment due to } \\
\text { climate change }\end{array}$ & 4.40 & 1.155 & High & 2 \\
\hline Q-19 & V.4 & $\begin{array}{l}\text { Considering the risk of climate change and sea } \\
\text { level rise on the city of Zuwara }\end{array}$ & 3.67 & .911 & High & 9 \\
\hline Q-21 & V.5 & Relying on personal exposure of climate change & 3.99 & .937 & High & 5 \\
\hline Q-22 & V.6 & $\begin{array}{l}\text { Awareness of precautions against climate } \\
\text { change within the city of Zuwara }\end{array}$ & 1.72 & 1.083 & Low & 16 \\
\hline Q-24 & V.7 & $\begin{array}{l}\text { Participation in precautions against climate } \\
\text { change within the city of Zuwara }\end{array}$ & 1.94 & 1.406 & Low & 15 \\
\hline Q-25 & V.8 & $\begin{array}{l}\text { Willingness to participate in precautions against } \\
\text { climate change }\end{array}$ & 3.92 & 1.346 & High & 6 \\
\hline Q-26 & V.9 & $\begin{array}{l}\text { Awareness to the effects of climatic conditions } \\
\text { of the city on the city's architecture }\end{array}$ & 3.20 & 1.518 & Medium & 10 \\
\hline Q-27 & V.10 & $\begin{array}{l}\text { Awareness to the effects of climate change on } \\
\text { the city's architecture. }\end{array}$ & 4.39 & 1.100 & High & 3 \\
\hline Q-28 & V.11 & $\begin{array}{l}\text { Awareness to the connection between climate } \\
\text { change and sea level rise }\end{array}$ & 3.80 & 1.363 & High & 7 \\
\hline Q-29 & V.12 & $\begin{array}{l}\text { Awareness to the impact of sea level rise to } \\
\text { areas under high exposure }\end{array}$ & 2.80 & 1.694 & Medium & 12 \\
\hline$Q-30$ & V.13 & $\begin{array}{l}\text { Connection to areas under high vulnerability to } \\
\text { sea level rise }\end{array}$ & 4.60 & 1.206 & High & 1 \\
\hline $\mathrm{Q}-32$ & V.14 & $\begin{array}{l}\text { Awareness to the connection between climate } \\
\text { change and floods the city has witnessed }\end{array}$ & 3.74 & 1.574 & High & 8 \\
\hline Q-33 & V.15 & $\begin{array}{l}\text { Experience with any effect of climate change, } \\
\text { sea level rise, or sea surges, regarding built } \\
\text { environment. }\end{array}$ & 2.14 & 1.621 & Low & 13 \\
\hline Q-34 & V.16 & $\begin{array}{l}\text { Awareness to possible precautions to be taken } \\
\text { against climate change. }\end{array}$ & 2.08 & 1.316 & Low & 14 \\
\hline \multicolumn{3}{|c|}{$\begin{array}{l}\text { Awareness of the problem of climate change and the danger of sea } \\
\text { level rise within the city of Zuwara. }\end{array}$} & 3.35 & 0.947 & \multicolumn{2}{|c|}{ Medium awareness } \\
\hline
\end{tabular}


From Table 2., it is evident that people's degree of awareness of the problem of climate change and the danger of sea level rise on the city of Zuwara is awareness of a medium degree, the average response of participants of the survey was (3.35), which is within the average variable numbers $(2.3334-3.6666)$ that could be seen in (Table 2$)$.

Regarding V.6 and V.7, 67\% of participants answered "No" to Q22 (Do you know of any measures to be taken in your city against climate change?); and $65 \%$ of the participants answered "No", to Q24 (Have you ever taken any measures out of concern of climate change?). These findings indicate a low level of awareness of precautions against climate change, as well as low participation in the V.6 and V.7 as shown in (Table 2).

In Q-34 (Many coastal cities around the world face the same danger, and some have developed plans to face it, do you have any information about the different strategies taken to face the problem?), which measures V.16, information was fed to the participant in the form of an illustration, (Figure 12) in order to raise their awareness to potential adaptation strategies, and to test their preferred method later on.

At this stage, no further explanation to the different strategies was done, as the purpose here was to measure existing awareness, however, later on, the same pictorial will be presented with more explanation in ( $Q$ 39).

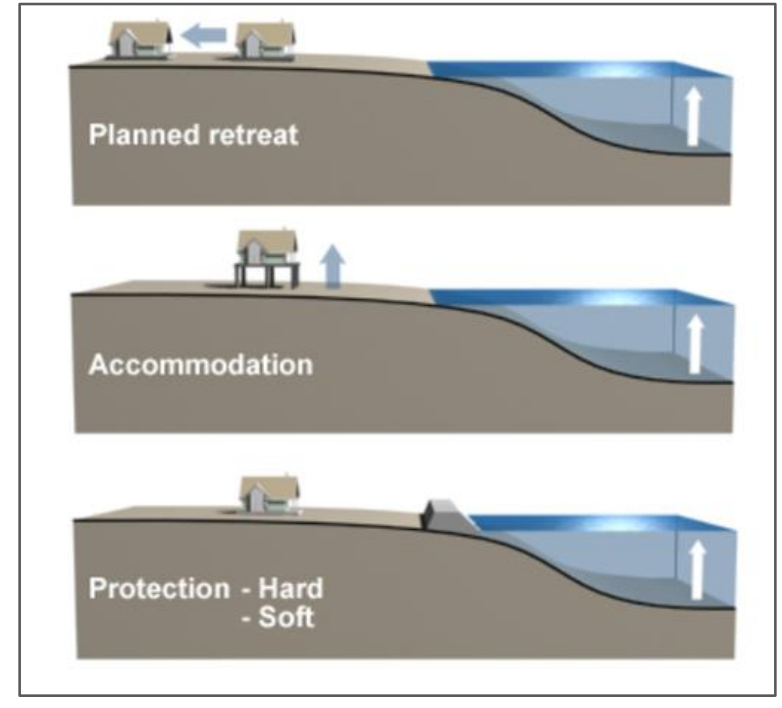

Figure 12 (Q34) possible precautions and adaptation methods

$55 \%$ of participants answered as "I have no information" to Q34, indicating a low awareness to possible precautions and adaptation methods V.16.

\subsubsection{Awareness regarding potential risks}

The participants of the survey proved that people of Zuwara have a high awareness regarding potential present and future risks to the city of Zuwara due to climate change, and have potential examples of these risks. $41 \%$ of the participants of the survey believe that land submersion is one of the most important risks that Zuwara city is exposed to as a result of climate change, it has been followed by drought 6\%, then desertification. Some participants of the survey have expressed concern with the risks of toxic fumes omitting from the Mellitah Factory (a natural gas plant 20 kilometers east of the city) and the Abu Kamash Factory (a chemical plant 30 kilometers west of the city). And the infrastructure of the city is another risk factor as well. 


\subsubsection{Awareness of signs of climate change}

Regarding the signs of climate change; "a change in weather and nature patterns", awareness to the different impacts of climate change observed by the participants of the survey, was the most observed with $46 \%$ of the participants expressing awareness towards it. While $42 \%$ of the participants expressed awareness to notable change in temperatures, and $29 \%$ of participants said they notice a change in rainfall and precipitation, however $12 \%$ of the participants surveyed expressed not witnessing any signs of climate change.

\subsubsection{Awareness regarding responsibility for action}

Results from that participants of the survey to the Q23 (who is responsible for taking action against climate change?) indicated that $26 \%$ of people of Zuwara, believes only local government, and decision makers, are responsible for taking actions. While $19 \%$ believes that only civilian and environmental organizations are responsible for making actions, and only $1 \%$ believes it's individual's responsibility to take action and $5 \%$ expressed lack of awareness to party responsible for action. However, majority of the participants surveyed $49 \%$ believes that responsibility for action is shared between local government and decision makers, civilian and environmental organizations, and individuals. All are responsible for taking measures.

\subsection{Measuring the Change in Awareness During Questionnaire Survey}

This part addresses the possible change in people's awareness of the climate change problem during the survey. In the second part of the survey, it has been asking after presenting information in the form of pictures, graphs, and simulations, to the impact of climate change on the city some general and specific questions has been asked to the respondents. This was done through questions in the second part which are Q28, Q29, Q32.

Q28: Did you know that the temperature of the planet and the seas are on the rise, and this warming raises the level of the seas and oceans?

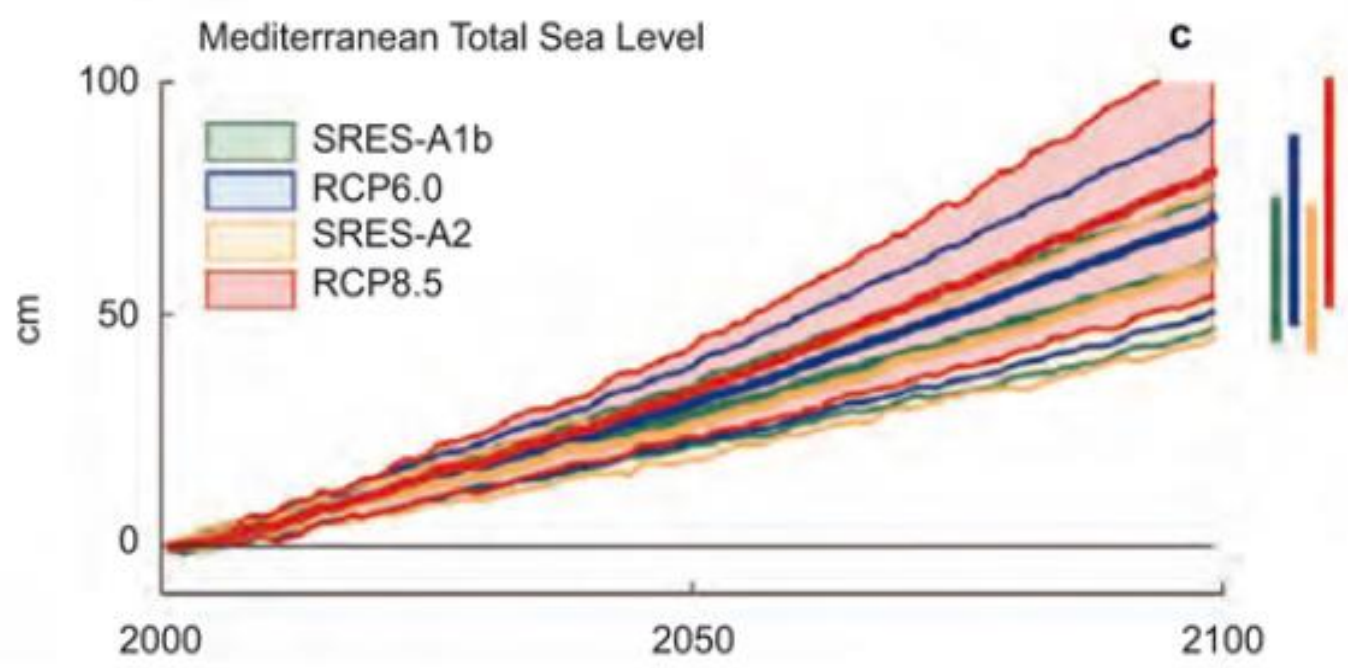

Figure 13 Q28. Presenting information about projected sea level rise, (Marcos, M., Jorda, G., \& Le Cozannet, G., 2018).

Q29: Due to climate change, sea levels may rise up to one meter in the upcoming decades, the red colored areas in the map are projected to be under sea level with one meter sea level rise, did you know about this danger before? 


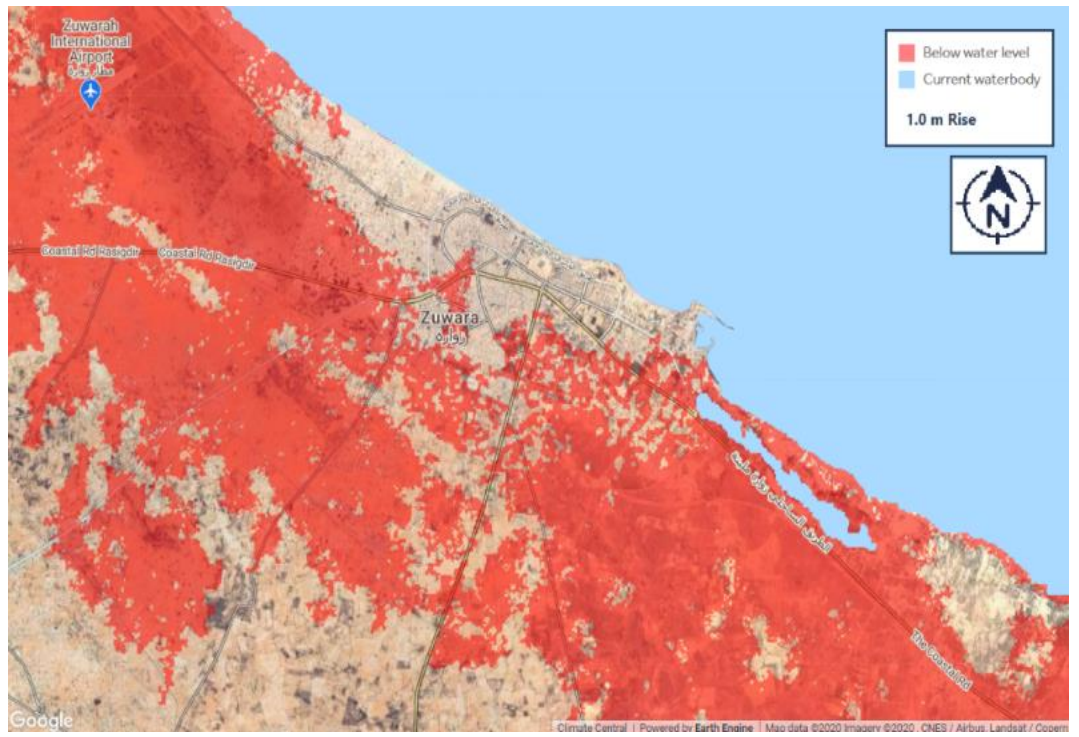

Figure 14 Q29. Presenting a simulation of projected impact of sea level rise on the city of Zuwara

Q32 Pictures of a sea water flood in the city of Zuwara in 2019, did you know that these floods are related to climate change and that they are expected to increase in intensity and frequency with the increasing temperature of the planet?
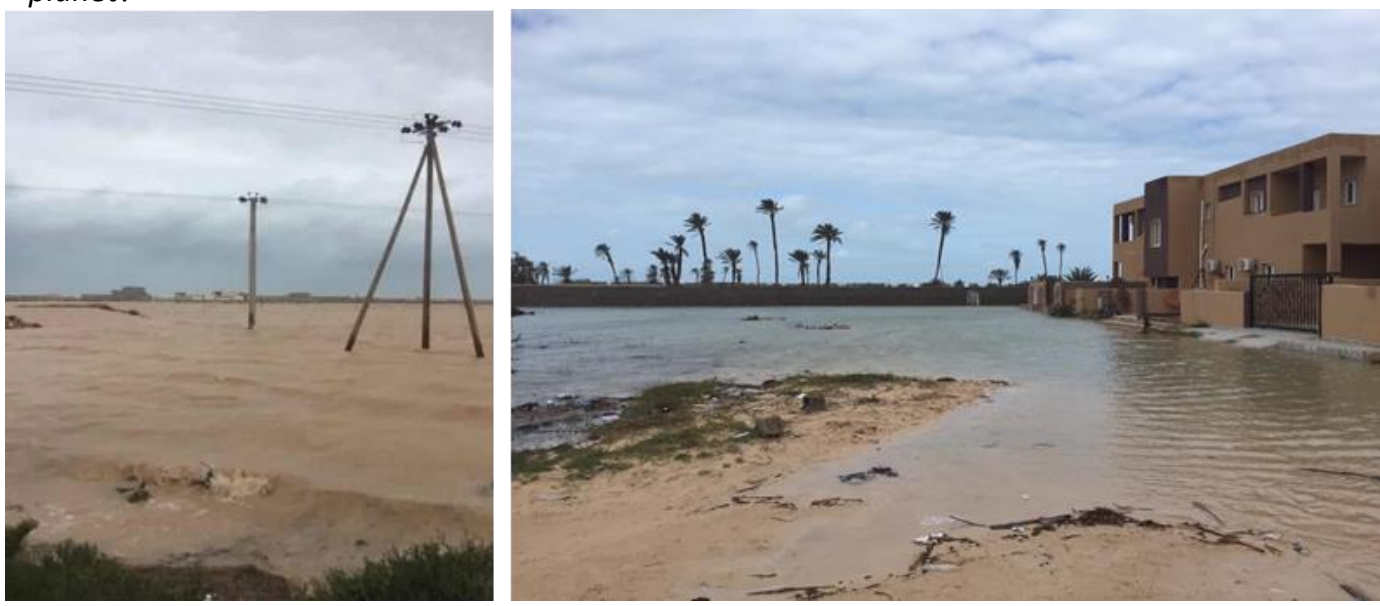

Figure 15 Q32. Shows the current impacts of climate change, represented in coastal floods, and threat to buildings.

After using the presented visual information and connecting them to architectural environment as a reference point, reassessment of the level of awareness is applied. For a higher level of awareness to be evident; statistically significant differences should be at the level of $(0.05)$ between the averages of the response of the participants of the survey before and after using the architectural environment as an educational tool on awareness of the problem of climate change. Paired-Sample-Test was applied, in order to identify the statistical significance of the differences between the responses of the participants of the survey to the following questions:

\subsubsection{Cross-Check Evaluation of Q19 and Q35}

As we introduced above, the question of "Do you believe the city of Zuwara to be at any risk either now or in the future due to climate change?", were asked twice with the numbers of Q19 and $Q 35$, before and after presenting the visual information on the risk of climate change on the city of Zuwara, using the architectural environment as an educational tool. This was done to measure (V.4) which considers the risk of climate change and sea level rise on the city of Zuwara. In the Q19 the mean was 3.67 and standard deviation was 0.911, while in the Q35 the mean is 4.02, with standard deviation of 0.816 . These results show that there was an average increase in 
consciousness of 0.35 , and a calculated significance level (Sig) of 0.000 , this result is statistically significant in favor of later variable. Figure 16 is a graph that shows the shift in answers to (Q19before) VS (Q35 -after).

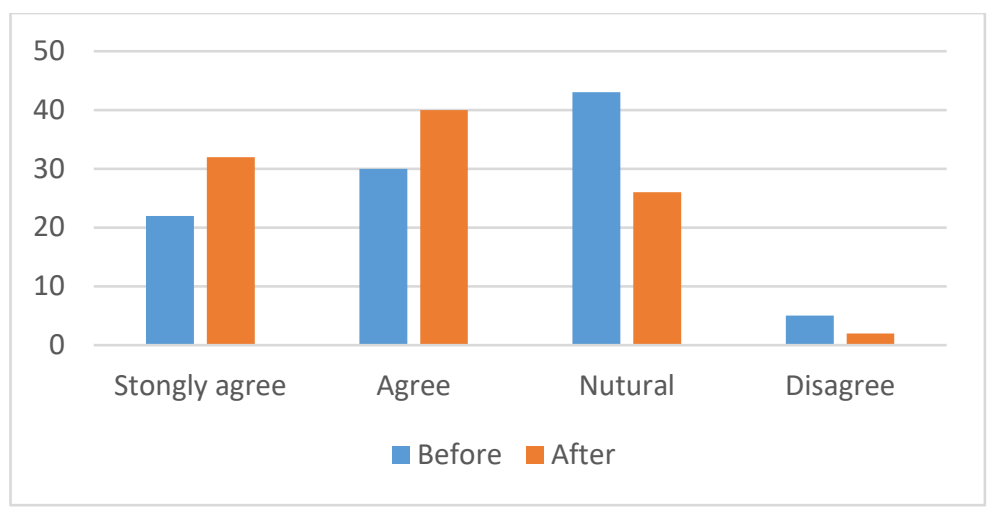

Figure 16 Difference in answers to Q19 (before) VS Q35 (after)

\subsubsection{Cross-Check Evaluation of Q21 and Q36}

With the number of Q21, this time the question is;

"Do you think climate change is or going to affect you or your family, personally?".

This form of question was given twice during the questionnaire, in Q21 and Q36, to measure the variable (V.5) which was relying on personal exposure of climate change. For the Q21 the mean was 3.99, and had a standard deviation of 0.957 , and for the Q36 the mean is 4.19 , with standard deviation of 0.837., This is meaning that there was an average increase in consciousness of 0.20 , and a calculated significance level (Sig) of 0.043 , this result is statistically significant in favor of later variable. Also in the Figure 17 there is a graph that shows the shift in answers to (Q21- before) VS (Q35 -after).

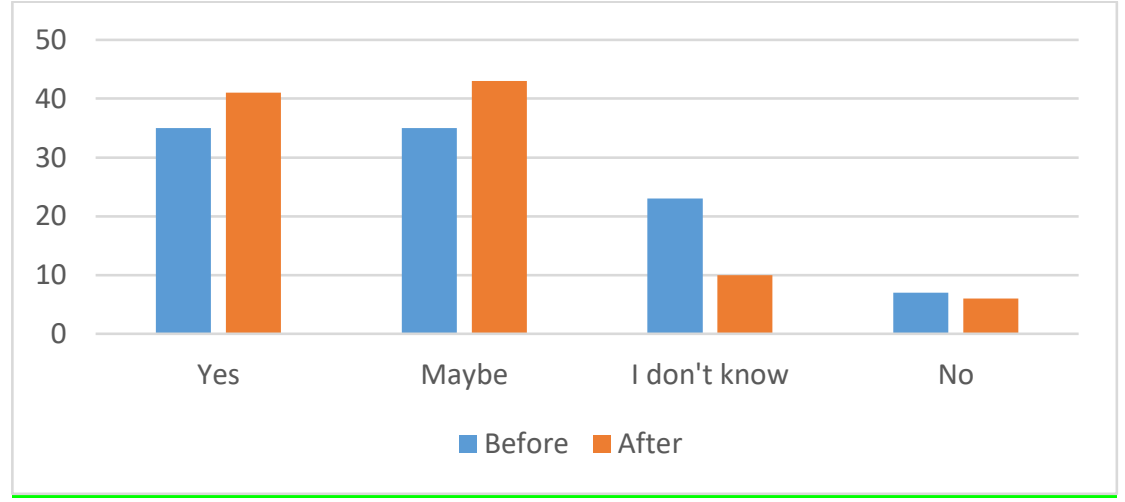

Figure 17 Difference in answers to Q21 (before) VS Q36 (after)

\subsubsection{Cross-Check Evaluation of $Q 21$ and $Q 37$}

In order to estimate the change in the level of awareness of the respondents, the Q21 was used here for the second time while the second part's question is different as Q37:

"Do you believe sea-level rise will pose a threat to the city of Zuwara and its residents?"

The variable to be measured was (V.5) personal exposure of climate change, against a larger scale exposure of climate change, including the entire city. Before using the architectural 
environment as an educational tool, the mean was 3.99, and had a standard deviation of 0.937, against consciousness to the risk of sea level rise, after, using the architectural environment as an educational tool, which had the mean of 4.75 , with standard deviation of 0.539 , meaning there was an average increase in consciousness of 0.75 , and a calculated significance level (Sig) of 0.000 , this result is statistically significant in favor of later variable.

The results of Paired-Sample-test, which are the means and the difference between them, standard deviations, significance levels (Sig) and the result, show an evident differences between the means of the participants of the survey responses to the questions $(35,36,37)$, and the means of the participants of the survey responses to the questions $(19,21)$, and that these differences are statistically significant at the level $(0.05)$, as the levels of the calculated significance $(0.000$, $0.043,0.000$ ) are all smaller than (0.05) and this indicates a substantial increase in the awareness of the survey respondents after using the architectural environment as an educative tool.

\subsection{Measuring People's Willingness for A Change}

To measure the level of people's willingness to make change; under the circumstance of change in level of awareness to climate change risks, the frequencies and percentages of participant's responses to questions 39 and 41 were calculated. These questions represent two variables: The first variable was to be measured the level of awareness about different methods and possible solutions to mitigate climate change and sea level rise effects on the city of Zuwara. In the (Figure 12 ), it can be seen the visual image of Q39. (Which of these methods do you think is better to be adopted to mitigate sea level rise?).

Pictorial explanation of Q39. Was presented in (Figure 12) to measures awareness about different methods proposed for mitigating the effects of climate change especially sea level rise.

At this stage, the different methods were explained as follows:

- Planned retreat: moving from high-risk to low-risk places.

- Accommodation: Modifying the building, for example; by following the raised building from the ground, or by using an underground waterproof floor.

- Protection: using dams and protection zones, strengthening the buffer zones between water and the coast, either by dams or restoring sand sediment.

Results from the survey indicate that (42\%) of the participants of the survey believe the best way to mitigate the problem is protection, by using dams and protection zones, strengthening the buffer zones between water and the coast. Either by dams or restoring sand sediment, which is a solution that can only be provided by governments and policy makers, meaning that the majority doesn't think it's within their capability to make actions that will significantly help the problem. Either for technical or financial reasons, (8\%) thinks accommodation and modifying the city's architecture is the preferred method for mitigation, and for (7\%) of the participants of the survey; planned retreat (moving from high risk to low risk places) was the method they believed to be best. However, since the second highest percentage of respondents (33\%), believes all methods of solutions must be applied, this indicates that people of the city are willing to participate in action against climate change effects as long as it is within a larger scheme, of which governments and policy makers have more responsibility of.

The second variable to be measured was the participants of the survey's willingness to make changes to their current or future houses, to help mitigate the problem. This was done through question 41:

"Q41: Would you be willing to make changes in your current or future house to help mitigate the problem, or do you think the government should be pushed to making the solutions?" 
The results indicate that (26\%) of the respondents to the survey appear to be willing to make changes, regardless of what the government does or does not do, while (36\%) of the respondents to the survey expresses willingness to act, but believe their actions alone are not enough and should only be a part of a bigger plan of action. (38\%) of the respondents were only willing to push the government to make solutions, and (10\%) of the respondents were passive towards any action.

The second variable indicates the same result as the first, which is medium willingness to take responsibility against risks to the city of Zuwara associated with climate change and sea level rise, and a higher willingness to work with in a larger frame of action.

\subsection{Measuring Level of Awareness Against Different Professional Backgrounds of The Participants}

To measure the effectiveness of professional backgrounded respondents as a variable in level of awareness to the effects of climate change and sea level rise, "Independent-Sample-Test" was applied on the survey data. In general, this method is including to identify the statistical significance of the differences and averages of responses of professionals and averages of non-professional's responses regarding awareness of the threat of climate change and sea level rise.

The results of the survey show that the (mean) of awareness of professionals is (3.6848), and that the (mean) of awareness of non-professionals is (3.2500), meaning the difference between the two averages is (0.43478) for the benefit of professionals, and it is also clear that the calculated level of significance ( $\mathrm{Sig}$ ) is equal to (0.001) and it is smaller than the assumed level of significance (Sig) which is equal to (0.05), and this indicates that the difference between the two averages is statistically significant. As a result of this evaluation, we can say that professionals are more aware than others on the risk of climate change and sea level rise. This is due to the fact that professionals in the fields of architecture, engineering and city planning have sufficient information and experience to realize the extent of the danger posed by climate change and sea level rise.

The significance of this is evident in the fact that although there is a noticeable difference in the level of awareness between the public and the professionals; however, the role of professionals in ways to overcome the risks of climate change is insufficient. According to the survey's findings when comparing responses of professionals to the variable of participation in precautions against climate change within the city of Zuwara; in their answers to Question (24) shown as a graph in (Figure 18).

"Q24 Have you ever taken any measures out of concern of climate change?"

We find that despite their awareness of the risks; their peruse to find solutions, or push for them, is not sufficient. As (56.5\%) of participants of the survey of professional backgrounds, expressed never participating in precautions against climate change effects to the city. And $(26.08 \%)$ expressed to have medium participation in precautions against climate change effects to the city, and only (17.39\%) expressed having high participation in precautions against climate change effects to the city in (Figure 18). 


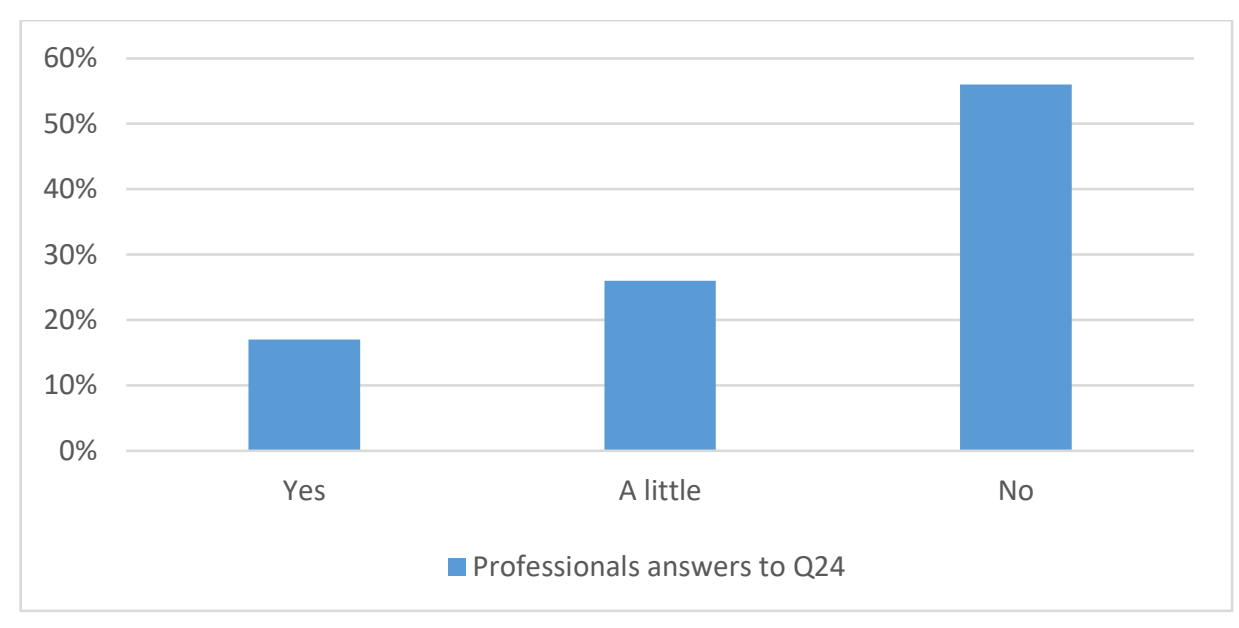

Figure 18 Q41. Professional's participation in precautions against climate change.

\section{Conclusion and Discussion}

When comparing the research hypotheses with the survey results, the research's main hypothesis, which states that architecture can be used as a tool to raise awareness of the dangers of climate change and sea-level rise, is a proven hypothesis, as it was evident when comparing the level of answers between participants of the survey before and after using architectural ideograms in the questions as an educational tool. It is obvious that the results indicated a substantial increase in the awareness of the study sample.

Regarding the sub-hypothesis, that of "public awareness of the dangers of climate change and sea-level rise is insufficient", it appears that an evidence for proving it is insufficient as it becomes clear to us that people's awareness of these risks exists at a medium level; it is subject to increase, but not absent.

Although there is a noticeable difference in the level of awareness between the public and the professionals. However, the hypothesis which says - "The role of professionals on the ways to overcome the risks of climate change is insufficient"- is a proven hypothesis according to the findings of the survey. Where answers of specialists to (Q-24) regarding the variable -"Participation in precautions against climate change within the city of Zuwara"- revealed an insufficient level of participation in precautions against climate change.

As for the hypothesis, "architecture can be used to motivate decision-makers to work on a strategy, to combat risks of climate change". Proof for it can be derived from responses to Q41, after using architecture to get the participants of the survey to an adequate level of awareness towards the risk of climate change on their built environment, they became eager to edge their governments to make solutions. This indicates an indirect positive relationship between using architecture as an educational tool to raise awareness and motivating decision-makers to work on mitigation and adaptation strategy.

The term climate change is discussed in educational circles more than any other, and it is much less discussed in social circles and amongst public, therefore, the implementation of pro-active communication strategies, to raise the public's level of awareness to the effects of climate change, and sea level rise, is highly desirable.

The connection between human and architecture is forceful, people of all backgrounds understand and relate to architecture and built environment. And the connection between 
architecture and climate change is quite significant as well. Therefore, architecture can represent a bridge that lets people stand face to face against climate change and start to be more aware and more willing to act upon this awareness, to participate in mitigation and adaptation strategies against climate change.

The importance of this research lies not only in climate change effects and risk of sea level rise on coastal cities, but also, the specific importance of the case study area. Since there is a noticeable lack of research on North African region and its coastal cities when it comes to climate change risks. Especially lack of information and previous research on Libya, where the vast majority of its people live in coastal cities. This study sheds light on these areas, and calls for more research to be done there.

\section{Future Recommendations for A Resilient Architectural Design and Planning in North African Coastal Cities}

Here, based on the findings and results of the research, we would like to make some suggestions to the scientific community in general, to the scientific bodies and specialists particularly working in Zuwara city, specialists working in related fields with architecture and politicians and decision makers.

Recommendations to the scientific community, in general, is to modify the methods of presenting scientific information and facts to the public to a more relatable manner, choosing tools which different people with different backgrounds will understand.

Recommendations for scientific bodies and specialists of Zuwara city, it is to conduct more detailed studies on the problems facing the region and to look at the successful experiences of other countries and study them and develop plans suitable for the area and then present them to decision-makers in order to come up with plans that will help in the mitigation and adaptation process.

Recommendations for specialists working in architecture and related fields such as engineering and urban planning; is to try and be a part of the solution, to utilize their specialties aiding better future scenarios, and to know that in order for architecture to raise people's awareness of climate change. The culture of architecture must move from the educational level to specialize in the local general level, so that people know the positive aspects of architecture and how it can play an important role in mitigating and /or adapting to climate change, especially in the long term.

Recommendations for decision makers to open dialogue between them and the public, to restore confidence, and to lay down plans to confront the threat that climate change poses to coastal cities in particular.

The study proposed the existence of a gap between the science of climate change and associated risks, and the public's awareness to it, suggesting using a familiar tool as the educative bridge that closes this gap, represented as "architecture". This research revealed that there is an urgent need for an action which pushes for pro-active communication strategies, between decision makers, scientific community, and the public, and for all stake holders to take initiatives towards putting mitigation and adaptation strategies into effectiveness, starting with higher level of awareness and willingness to act. 


\section{References}

Ahmed, A. Q., \& Zaied, M. A. (2012). The emergence and formation of coastal Sabkhas north of western Libya. Academic Research Journal, 9, 234-257.

Bord, R. J., Fisher,A. \& Robert, E.O. (1998). Public perceptions of global warming: United States and international perspectives, Climate research, 11, (1), 75-84.

Climate Central, (2014). Coastal Climatecentral Org https://coastal.climatecentral.org/map/13/12.1012/32 .9248/?theme=sea_level_rise\&map_type=coastal_dem_comparison\&basemap=roadmap\&contiguou $\mathrm{s}=$ true\&elevation_model=best_available\&forecast_year=2100\&pathway=rcp45\&percentile=p50\&ref resh=true\&return_level=return_level_1\&slr_model=kopp_2014

Helmey, Y, (2021). Memory of Zuwara, book in publication process.

Lorenzoni, I. \& Pidgeon, N. F. (2006). Public Views on Climate Change: European and USA Perspectives. Climatic Change, 77, 73-95. https://doi.org/10.1007/s10584-006-9072-z

Libyan Educational Curricula and Research Center, (2019), Geography of Libya, 14-19.

Lieske, D. J. (2012). Towards a framework for designing spatial and non-spatial visualizations for communicating climate change risks, Geomatica, 66, (1), 27-36.

Marcos, M., Jorda, G., \& Le Cozannet, G. (2018). Sub-chapter 2.2.1. Sea level rise and its impacts on the Mediterranean [E-book]. The Mediterranean region under climate change (pp. 265-275). IRD Éditions. https://doi.org/10.4000/books.irdeditions.22908

Maul G.A., Duedall I.W. (2019) Demography of Coastal Populations. In: Finkl C.W., Makowski C. (eds) Encyclopedia of Coastal Science. Encyclopedia of Earth Sciences Series. Springer, Cham. https://doi.org/10.1007/978-3-319-93806-6_115

Poleservice - consulting office, Bureau of municipal projects wadeco, warsaw-poland. (1988). Tripoli region development plans- Zuwara sub-region (Vol. 1, NO.2). Libyan General Facilities Committee.

Thead, E.A. (2016) Sea Level Rise: Risk and Resilience in Coastal Cities, publication of the climate Institute, 1400, 16th suite 430, Washington DC 20036.

Whitmarsh,L. , Upham, P. (2013). 2 Public responses to climate change and low-carbon energy, Low-Carbon Energy Controversies, 14. 10.4324/9780203105153.

\section{Resume}

Manal Emhemed Mu Chalgham, is currently a Graduate student at Okan University, Institute of Sciences, and Department of Architecture with a thesis topic discussing the relationship between "Architecture" and awareness of climate change. She has obtained an undergraduate degree in technical engineering and architecture from the College of Engineering Technology in Zuwara. Hometown: Zuwara / Libya. Interested in researching topics of sustainable architecture and urban resilience against climate change.

Bahar Başer Kalyoncuoğlu, is a landscape architect and academician. She had the bachelor degree from Department of Landscape Architecture at Istanbul University (1999) and MSc Degree from Landscape Planning Graduate Programme from Department of Urban and Regional Planning at Istanbul Technical University. Her Phd is also from ITU' Landscape Architecture Programme. Since 2002, she has been giving courses to the Architecture, Urban and Regional Planning, Landscape Architecture and Urban Design Departments, at ITU, Okan University and Medipol University in Istanbul, Turkey. Recently, she is an Assistant Professor at Istanbul Medipol University, Department of Urban Design and Landscape Architecture and has numerous publications on a variety of research areas such as urban landscape, urban ecology, urban agriculture, cultural landscapes, sustainable landscape planning and landscape architecture education. 